\title{
The Importance of Vascular Endothelial Growth Factor as a Marker of Angiogenesis and Lymphangiogenesis in Non-small Cell Lung Cancer
}

\author{
Suciu Bogdan Andrei*, Denes Lorand, Hălmaciu loana, Mezei Tibor, Brînzaniuc Klara, Azamfirei Leonard
}

University of Medicine and Pharmacy of Tirgu Mures

Lung cancer is the main cause of cancer death both in men and women. In spite of progress seen in the early diagnosis of lung cancer, and implementation of new treatment principles for these patients, 5 year survival of non-small cell lung cancer patients undergoing surgery is low. Introduction of anti-angiogenic therapy administered concomitantly with conventional chemotherapy agents represented practically the first success seen in the treatment of lung cancer in the last 20 years. The aim of this paper is to review the literature informations about the importance of VEGF (vascular endothelial growth factor) as a marker of angiogenesis in patients with non-small cell lung cancer. Therefore, we practiced a literature review about these topics : the importance of VEGF in tumor angiogenesis and lymphangiogenesis in patients with non-small cell lung cancer and his importance as a prognostic factor at these patients, the prognostic impact of serum levels of VEGF and of the cellular expression of VEGF at these patients and also we reviewed the value of the antiangiogenic therapy.

Keywords: angiogenesis, lymphangiogenesis, non-small cell lung cancer

Rreceived: 11 June 2015 / Accepted: 05 August 2015

\section{Introduction}

Lung cancer is the main cause of cancer death both in men and women [1]. According to 2006 European statistical data, 1.7 million people died of cancer in Europe, and approximately $20 \%$ of these deaths were caused by lung cancer [2]. With the increase of the incidence of smoking in developing countries, the incidence of lung cancer increased exponentially [3]. In spite of progress seen in oncologic therapies during the last decades, average survival of patients undergoing surgery for non-small cell lung cancer showed an average increase of 1-2 years, but the 5 year survival did not change. One of the most important achievements implemented during the last 20 years in the treatment of non-small cell lung cancer was the introduction of anti-angiogenic therapy and tyrosine-kinase inhibitors.

In spite of progress seen in the early diagnosis of lung cancer, and implementation of new treatment principles for these patients, 5 year survival of non-small cell lung cancer patients undergoing surgery is low ( $7 \%$ to $14 \%$ ) [4]. Introduction of anti-angiogenic therapy administered concomitantly with conventional chemotherapy agents represented practically the first success seen in the treatment of lung cancer in the last 20 years [5].

\section{Material and methods}

In order to perform this study we search for articles in sciencedirect.com. We used articles published in English. Searches was conducted on the following terms : non-

* Correspondence to: Bogdan Andrei Suciu

E-mail: suciubogdanandrei@yahoo.com small cell lung cancer, angiogenesis, vascular endothelial growth factor. We used 68 studies published between 2000 and 2015.

\section{The importance of VEGF in tumor angiogenesis and lymphangiogenesis}

Tumor angiogenesis is the development of new vessels from pre-existing vessels in the tumor [6]. The importance of angiogenesis in cancer pathogenesis has been demonstrated by several authors, who have shown that development of tumors over the size of $2 \mathrm{~mm}$ depends on the presence of tumor neovascularization [7]. At the same time, the presence of multiple cytokines has been demonstrated that are produced by tumor cells and stimulate tumor angiogenesis. Besides stimulating development of new vessels in the tumor, these cytokines increase capillary permeability, enhance tumor invasion and development of tumor metastases [8]. Recent studies demonstrate that the mechanisms that trigger tumor angiogenesis are similar to those that trigger tumor lymphangiogenesis $[9,10]$.

The major cytokine that stimulates tumor angiogenesis is VEGF (vascular endothelial growth factor). Currently 5 different types of VEGF (A,B,C,D and E) are known. Of these 5 different types of VEGF, the most important role in angiogenesis is played by VEGF-A [8]. Certain authors demonstrated that VEGF is also involved in modulation of lymphangiogenesis (through VEGF-C and VEGF-D) [11]. In approximately $30-40 \%$ of the non-small cell lung cancer patients enhanced VEGF-A expression is seen in tumor cells, accompanied by increased angiogenic activity $[8,12,13]$. Regarding the role of VEGF-C in modulat- 
ing lymphangiogenesis, there is no unanimously accepted agreement, even if most of the authors admit its role in tumor lymphangiogenesis modulation [14].

Structurally VEGF is a glycoprotein. VEGF is secreted by endothelial cell, macrophages, stromal cells and tumor cells as well. It stimulates endothelial cell proliferation and migration, increases vascular permeability, and stimulates stromal degradation through activation of certain proteolytic enzymes $[15,16]$. The role of VEGF in stimulation of the development of new vessels is important both during physiological, and pathological processes [17].

VEGF binds to three types of receptors: VEGFR-1, -2 and -3 (vascular endothelial growth factor receptor) $[18,19]$. While VEGF-A and VEGF-B bind VEGFR-1 and VEGFR-2, VEGF-C and VEGF-D bind to VEGFR-2 and VEGFR-3 [20]. This group of receptors belongs to the tyrosine-kinase receptor group [21]. VEGFR-2 is the main pro-angiogenic receptor, and plays an important role in triggering tumor neo-angiogenesis [22]. Regarding non-small cell lung cancer, the existence of VEGFR-2 has been demonstrated in the membranes of tumor cell, in their cytoplasm and in newly developed vessels inside the tumor; these facts demonstrate the role of VEGF, and tumor angiogenesis in lung cancer pathogenesis [23]. Nevertheless, even if an intense VEGFR-2 expression has been demonstrated in lung cancer patients, most of the studies have shown that this marker does not correlate with the prognosis of these patients [24]. On the contrary, other studies have demonstrated that VEGFR-2 and VEGFR-3 blockade may have beneficial effects on the invasive and metastatic properties of the tumors $[25,26]$. In vivo and in vitro studies demonstrate that VEGF-C binding to the VEGFR-3 stimulates motility of tumor cells, which enhances metastatic properties [27].

The first study to demonstrate the importance of VEGF as marker of tumor angiogenesis in non-small cell lung cancer patients was published by Mattern in 1996 [28]. Since then, several reports have been published demonstrating the relationship between cellular expression and blood levels of VEGF, as prognosis factors in non-small cell lung cancer patients. The results were contradictory as in certain studies cellular expression of VEGF correlated with a poor prognosis for these patients [29,30], while other authors concluded that there is no correlation with the long term prognosis of these patients [29,31]. Additionally, there are significant differences regarding the importance of VEGF as prognosis factor, and the histological type of lung cancer. Some authors suggested that VEGF is a negative prognosis factor only for patients with lung adenocarcinomas, and not those with squamous cell carcinomas [32]. After reviewing the literature we found that there are more studies that show the relationship between cellular expression or blood levels of VEGF that correlate with a poor prognosis for non-small cell lung cancer patients, compared to the number of studies demonstrating that VEGF expression does not correlate with the prognosis of these patients [29-31].

\section{The importance of VEGF as prognosis factor in non-small cell lung cancer patients}

Currently there are two published meta-analysis studies that deal with the importance of VEGF as prognosis marker in non-small cell lung cancer patients; the first was authored by Delmotte (2002, 1549 patients) and the other by Zhan (2009, 4499 patients). Both meta-analysis studies conclude that cellular expression of VEGF, and its blood levels are poor prognosis factors for patients diagnosed with lung cancer $[33,34]$.

There are differences in the importance as prognosis factors of different VEGF subtypes, as well as in the importance of disease stage in non-small cell lung cancer patients. Therefore, certain authors suggest that VEGF$\mathrm{A}$ is a negative prognosis factor for lung adenocarcinoma patients, while VEGF-C is a negative prognosis factor for squamous cell carcinoma patients [35]. Currently there is no consensus regarding the correlation between the histological type of lung cancer and cellular expression of a certain VEGF subtype [36].

Unlike VEGF-A that only stimulates tumor angiogenesis, VEGF-C stimulates lymphangiogenesis as well, and thus the lymphatic metastatic properties of the tumor [37]. Certain authors suggest that VEGF-B and D are factors of poor prognosis for patients with stage I and II of the disease, but for stage III and IV patients, cellular expression of VEGF-D represents a factor of good prognosis [38].

Currently it is unanimously accepted that invasive or metastatic properties of a tumor are associated with a poor prognosis. Numerous authors observed the fact that binding of VEGF to its receptor is a crucial moment of the tumor metastasis process $[39,40]$. Other authors suggest that the importance of VEGF-A as a negative prognosis factor for these patients is also due to the fact that cellular expression of VEGF-A correlates with lymph node metastases [41].

\section{Measurement of serum levels and identification of cellular expression of VEGF in non-small cell lung cancer patients}

Numerous debates surround the methods of approach to the impact of VEGF and angiogenesis in non-small cell lung cancer patients. These controversies are especially about the best method of EGFR expression detection [46]. Certain authors recommend immunohistochemical methods for detection of EGFR expression in tumor cells. The critics of these methods argue with the fact that immunohistochemical methods are semi-quantitative and most often, exact evaluation of angiogenesis is difficult in these cases $[46,47]$. This is one of the reasons that were incriminated by some studies for not being able to obtain direct correlations between cellular expression of VEGF and prognosis of patients included in the study [47]. On the other hand, other authors think that immunohistochemical methods are very useful for the study of tumor microvascular density, and of tumor neo-angiogenesis [48]. 
Other authors recommend measurement of serum VEGF levels, which allows a more exact quantification of VEGF [8]. This method is also not accepted unanimously, because coagulation occurring after blood sampling may alter serum VEGF levels. During coagulation, large quantities of VEGF are released from the leucocytes and platelets. Thus, certain authors suggest that serum VEGF levels returned by the assays are made up rather by VEGF contents of blood cell components, and in a less proportion by cellular expression [49,50]. Nevertheless, certain studies observed that serum VEGF levels represent a negative prognosis factor for non-small cell lung cancer patients, even if these observations are currently not accepted unanimously [51]. Likewise, certain authors suggest that preoperatively decreased serum VEGF levels correlate with a favorable response to chemotherapy with platinum derivatives, and it also represents a good prognosis for these patients [51,52]. There are studies that look into a possible relationship between serum VEGF levels and tumor stage in non-small cell lung cancer patients. There controversies in the literature about the existence of such relationship; some studies suggest that serum VEGF levels correlate with tumor stage, but others negate that $[53,54]$. It is unanimously accepted that serum VEGF levels correlate with tumor size; this claim is supported by the fact that practically VEGF is secreted by the tumor cells [55].

Certain authors observed that in lung cancer patients with paraneoplastic pleural effusion (i.e. advanced disease stage), VEGF levels of the pleural fluid were increased, and correlated with the disease stage and long term survival of these patients [56]. Increased VEGF titers of the pleural fluid are caused by increased cellular expression of VEGF in mesothelial cells of the pleural membranes [57]. Consequently, certain authors recommend measurement of pleural fluid VEGF titers in case of such patients.

Currently, the molecular mechanisms of metastatic spreading of tumor cells in non-small cell lung cancer patients are not fully understood [58]. One of the possible mechanisms contributing to metastasis formation is the existence of intensive angiogenic and lymphangiogenic processes in the tumor $[59,60]$. Tumor cell migration into lymph nodes is stimulated by the activation of VEGF$\mathrm{C}$ and its receptor, VEGFR-3 [61,62]. A crucial role in lymphangiogenesis stimulation is played by VEGF-D; together with VEGF-C, this molecule causes dilatation of peritumoral lymphatics, which may lead to development of tumor metastases $[63,64]$.

\section{Antiangiogenic therapy}

The first studies about the significance of angiogenesis in patients with neoplastic disease were published by Folkmann in 1971. He suggested that tumor growth can be stopped by inhibition of the development of new vessels [7]. The interest for angiogenesis studies in patients with neoplastic disease increased dramatically with the introduction of anti-angiogenic therapies. Thus, certain authors demonstrated that medications capable of blocking VEGF binding to its receptor (VEGFR), inhibit tumor growth and have beneficial effects in cancer patients [65]. The first angiogenesis inhibitor introduced into medical practice was bevacizumab (a monoclonal antibody that binds to VEGF) [66]. Concomitant administration of bevacizumab with conventional chemotherapy has lead to a global increase of approximately 1 year in survival of non-small cell lung cancer patients [67]. These results lead to the introduction of bevacizumab administered concomitantly with platinum derivatives as first line medications in non-small cell lung cancer patients both in the European Union and the United States [68].

\section{Conclusions}

The majority of published studies consider that serum VEGF levels, and VEGF expression in tumor cells is a negative prognosis factor for non-small cell lung cancer patients. Beneficial effects of anti-angiogenic therapies seen in some non-small cell lung cancer patients calls for new randomized studies aimed at identification of patients as candidates of routine anti-angiogenic therapy.

\section{Acknowledgement}

This paper is supported by the Sectoral Operational Programme Human Resources Development (SOPHRD), financed from the European Social Fund and by the Romanian Government under the contract number POSDRU/159/1.5/S/133377/.

\section{References}

1. Jemal A, Murray T, Ward E, et al. Cancer statistics. CA Cancer J Clin. 2005;55:10-30.

2. Ferlay J, Autier P, Boniol M, Heanue M, Colombet M, Boyle P. Estimates of the cancer incidence and mortality in Europe in 2006. Ann Oncol. 2007;18:581-592.

3. Frank C Detterbeck, Sandra Zelman Lewis, Rebecca Diekemper, Doreen Addrizzo Harris, Michael Alberts. Diagnosis and Management of lung Cancer, 3rd ed. American College of Chest Physicians. EvidenceBased Clinical Practice Guidelines. Chest. 2013;143(5_suppl):7S-37S.

4. Howard BA, Furumai R, Campa MJ, et al. Stable RNA interferencemediated suppression of cyclophilin A diminishes non-small-cell lung tumor growth in vivo. Cancer Res. 2005;65:8853-8860.

5. Sandler A, Gray R, Perry MC, et al. Paclitaxel carboplatin alone or with bevacizumab for non-small-cell lung cancer. $N$ Engl J Med. 2006;355:2542-2550

6. Aita M, Fasola G, Defferrari C, et al. Targeting the VEGF pathway: Antiangiogenic strategies in the treatment of non-small cell lung cancer. Critical Reviews in Oncology/Hematology. 2008;68:183-196.

7. Folkman J. Tumor angiogenesis: therapeutic implications. $N$ Engl J Med. 1971;285:1182-1186.

8. Bremnes RM, Camps C, Sirera R. Angiogenesis in non-small cell lung cancer: The prognostic impact of neoangiogenesis and the cytokines VEGF and bFGF in tumours and blood. Lung Cancer. 2006;41:143-158.

9. Hirakawa S, Kodama S, Kunstfeld $R$, et al. VEGF-A induces tumor and sentinel lymph node lymphangiogenesis and promotes lymphaticmetastasis. J ExpMed. 2005;201:1089-1099.

10. Kawai H, Minamiya Y, Ito M, et al. VEGF121 promotes lymphangiogenesis in the sentinel lymph nodes of non-small cell lung carcinoma patients. Lung Cancer 2008;59:41-47.

11. Karkkainen MJ, Petrova TV. Vascular endothelial growth factor receptors in the regulation of angiogenesis and lymphangiogenesis. Oncogene. 2000;19:5598-5605.

12. O'Byrne KJ, Koukourakis MI, Giatromanolaki A, et al. Vascular endothelial growth factor, platelet-derived endothelial cell growth 
factor and angiogenesis in non-small-cell lung cancer. $\mathrm{Br} \mathrm{J}$ Cancer. 2000;82:1427-1432.

13. Giatromanolaki A, Koukourakis Ml, Sivridis E, et al. Invading edge vs. inner (edvin) patterns of vascularization: an interplay between angiogenic and vascular survival factors defines the clinical behaviour of non-small cell lung cancer. J Pathol. 2000;192:140-149.

14. Takizawa $\mathrm{H}$, Kondo $\mathrm{K}$, Fujino $\mathrm{H}$, et al. The balance of VEGF-C and VEGFR-3mRNA is a predictor of lymph nodemetastasis in non-small cell lung cancer. Br J Cancer. 2006;95:75-79.

15. Choi JH, Kim HC, Lim HY, et al. Vascular endothelial growth factor in the serum of patients with non-small cell lung cancer: correlation with platelet and leukocyte counts. Lung Cancer. 2001;33(2-3):171-179.

16. Fontanini G, Vignati S, Boldrini L, et al. Vascular endothelial growth factor is associated with neovascularization and influences progression of non-small cell lung carcinoma. Clin Cancer Res 1997;3(6):861-865.

17. Ferrara N, Henzel WJ. Pituitary follicular cells secrete a novel heparinbinding growth factor specific for vascular endothelial cells. Biochem Biophys Res Commun. 1989;161:851-858.

18. De Vries $\mathrm{C}$, Escobedo JA, Ueno $\mathrm{H}$, et al. The fms-like tyrosine kinase, a receptor for vascular endothelial growth factor. Science. 1992;255:989-991.

19. Millauer B, Wizigmann-Voos S, Schnurch $\mathrm{H}$, et al. High affinity VEGF binding and developmental expression suggest Flk-1 as a major regulator of vasculogenesis and angiogenesis. Cell. 1993;72:835-846.

20. Achen MG, Mann GB, Stacker SA. Targeting lymphangiogenesis to prevent tumour metastasis. Br J Cancer. 2006;94:1355-1360.

21. Jenny B, Harrison JA, Baetens D, Tille JC, Burkhardt $K$, Mottaz $\mathrm{H}$, et al. Expression and localization of VEGF-C and VEGFR-3 in glioblastomas and haemangioblastomas. J Pathol. 2006;209:34-43.

22. Cascone T, Troiani T, Morelli MP, Gridelli C, Ciardiello F. Antiangiogenic drugs in non-small cell lung cancer treatment. Curr Opin Oncol. 2006; 18:151-155

23. Seto T, HigashiyamaM, Funai $\mathrm{H}$, Imamura $\mathrm{F}$, Uematsu $\mathrm{K}$, Seki N, et al. Prognostic value of expression of vascular endothelial growth factor and its flt-1 and KDR receptors in stage I non-small-cell lung cancer. Lung Cancer. 2006;53:91-96.

24. Decaussin M, Sartelet H, Robert C, MoroD, Claraz C, Brambilla C, et al. Expression of vascular endothelial growth factor (VEGF) and its two receptors (VEGFR1-Flt1 and VEGF-R2-Flk1/KDR) in non-small cell lung carcinomas (NSCLCs): correlation with angiogenesis and survival. J Pathol. 1999;188:369-377.

25. Wang S, Liu H, Ren L, Pan Y, Zhang Y. Inhibiting colorectal carcinoma growth and metastasis by blocking the expression of VEGF using RNA interference. Neoplasia. 2008; 10:399-407.

26. Chen Y, Stamatoyannopoulos G, Song CZ. Down-regulation of CXCR4 by inducible small interfering RNA inhibits breast cancer cell invasion in vitro. Cancer Res. 2003;63:4801-4804.

27. Feng $\mathrm{Y}, \mathrm{Hu} \mathrm{J}, \mathrm{Ma} \mathrm{J}$, et al. RNAi-mediated silencing of VEGF-C inhibits non-small cell lung cancer progression by simultaneously downregulating the CXCR4, CCR7, VEGFR-2 and VEGFR-3-dependent axes-induced ERK, p38 and AKT signalling pathways, Eur J Cancer. 2011;47:2353-2363.

28. Mattern J, Koomägi R, Volm M. Association of vascular endothelial growth factor expression with intratumoral microvessel density and tumour cell proliferation in human epidermoid lung carcinoma. $\mathrm{Br} J$ Cancer. 1996;73:931-934.

29. Farhat FS, Tfayli A, Fakhruddin N, et al. Expression, prognostic and predictive impact of VEGF and bFGF in non-small cell lung cancer, Clinical Reviews in Oncology/Hematology. 2012,84:149-160.

30. Kadota K, Huang CL, Liu D, et al. The clinical significance of lymphangiogenesis and angiogenesis in non-small cell lung cancer patients. Eur J Cancer. 2008;44:1057-1067.

31. Liao M, Wang H, Lin Z, Feng J, Zhu D. Vascular endothelial growth factor and other biological predictors related to the postoperative survival rate on non-small cell lung cancer. Lung Cancer. 2001;33:125-132.

32. Pajares MJ, Agorreta J, Larrayoz M, et al. Expression of tumorderived vascular endothelial growth factor and its receptors is associated with outcome in early squamous cell carcinoma of the lung. J Clin Oncol. 2012;30:1129-1136.

33. Delmotte P, Martin B, Paesmans M, et al. VEGF and survival of patients with lung cancer: a systematic literature review and meta-analysis. Rev Mal Respir. 2002;19:577-584.

34. Zhan P, Wang J, Lv XJ, Wang Q, Qiu LX, Lin XQ, et al. Prognostic value of vascular endothelial growth factor expression in patients with lung cancer: a systematic review with meta-analysis. J Thorac Oncol. 2009;4:1094-1103.

35. Nakashima T, Huang CL, Liu D, Kameyama K, Masuya D, Ueno M, et al. Expression of vascular endothelial growth factor-A and vascular endothelial growth factor- $\mathrm{C}$ as prognostic factors for non-small cell lung cancer. Med Sci Monit.2004;10:BR157-165.

36. Dziadziuszko R, Chyczewski L, Jassem E, Jassem J. Expression of vascular endothelial growth factor (VEGF) and its receptor FLK1 in non-small cell lung cancer (NSCLC) - a preliminary report. Folia HistochemCytobiol. 2001;39(Suppl. 2):100-101.

37. Padera TP, Kadambi A, di Tomaso E, et al. Lymphatic metastasis in the absence of functional intratumor lymphatics. Science. 2002;296:18831886.

38. Carrillo de Santa Pau E, Arias FC, Caso Peláez E, Munoz Molina GM, Sánchez Hernández I, Muguruza Trueba I, et al. Prognostic significance of the expression of vascular endothelial growth factors A, B, C, and D and their receptors R1, R2, and R3 in patients with nonsmall cell lung cancer. Cancer. 2009;115:1701-1712

39. Avraham H, Park SY, Schinkmann K, Avraham S. RAFTK/Pyk2mediated cellular signalling. Cell Signal. 2000;12:123-133.

40. Burton JB, Priceman SJ, Sung JL, et al. Suppression of prostate cancer nodal and systemic metastasis by blockade of the lymphangiogenic axis. Cancer Res. 2008;68:7828-7837.

41. Donnem T, Al-Shibli K, Al-Saad C, Delghandi MP, Busund LT, Bremnes RM. VEGF-A and VEGFR-3 correlate with nodal status in operable nonsmall cell lung cancer: Inverse correlation between expression in tumor and stromal cells, Lung Cancer. 2009;63:277-283.

42. Yilmaz A, Ernam D, Unsal E, Demirag F, Atikcan S, Tastepe I. Vascular Endothelial Growth Factor Immunostaining Correlates with Postoperative elapse and Survival in Non-Small Cell Lung Cancer, Arch Res med. 2007;38:764-768.

43. Volm M, Koomägi R, Mattern J. Prognostic value of vascular endothelial growth factor and its receptor Flt-1 in squamous cell lung cancer. Int $J$ Cancer. 1997;74:64-68.

44. Imoto H, Osaki T, Taga S, Ohgami A, Ichiyoshi Y, Yasumoto K. Vascular endothelial growth factor expression in non-small-cell lung cancer: prognostic significance in squamous cell carcinoma. J Thorac Cardiovasc Surg. 1998;115:1007-1014.

45. Yuan A, Yu CJ, Shun CT, Luh KT, Kuo SH, Lee YC, et al. Total cyclooxygenase-2 mRNA levels correlate with vascular endothelial growth factor mRNA levels, tumor angiogenesis and prognosis in nonsmall cell lung cancer patients. Int J Cancer. 2005;115:545-555.

46. Jelkmann W. Pitfalls in the measurement of circulating vascular endothelial growth factor. Clin Chem. 2001;47:617-623.

47. Bonnesen B, Pappot H, Holmstav J, Guldhammer Skov B. Vascular endothelial growth factor $\mathrm{A}$ and vascular endothelial growth factor receptor 2 expression in non-small cell lung cancer patients: Relation to prognosis, Lung Cancer. 2009,66:314-318.

48. Liao M, Wang H, Lin Z, Feng J, Zhu D. Vascular endothelial growth factor and other biological predictors related to the postoperative survival rate on non-small cell lung cancer. Lung Cancer. 2001;33(2-3):125-132.

49. Hormbrey E, Gillespie P, Turner K, et al. A critical review of vascular endothelial growth factor (VEGF) analysis in peripheral blood: is the current literature meaningful? Clin Exp Metastasis. 2002;19:651-663.

50. Webb NJ, Bottomley MJ, Watson CJ, Brenchley PE. Vascular endothelial growth factor (VEGF) is released from platelets during blood clotting: implications for measurement of circulating VEGF levels in clinical disease. Clin Sci (Lond). 1998;94:395-404.

51. Sorreensen $\mathrm{S}$, Fohlin $\mathrm{H}$, Lindgren $\mathrm{A}$, et al. Predictive role of plasma vascular endothelial growth factor for the effect of celecoxib in advanced non-small cell lung cancer treated with chemotherapy, Eur J Cancer. 2013;49:115-120

52. Kumar S, Guleria R, Singh V, Bharti AC, Mohan A, Das BC. Efficacy of plasma vascular endothelial growth factor in monitoring first-line chemotherapy in patients with advanced non-small cell lung cancer. BMC Cancer. 2009;9:421.

53. Ohta $\mathrm{Y}$, Watanabe $\mathrm{Y}$, Murakami $\mathrm{S}$, et al. Vascular endothelial growth factor and lymph node metastasis in primary lung cancer. $\mathrm{Br} \mathrm{J}$ Cancer. 1997;76(8):1041-1045.

54. Brattstrom D, Bergqvist M, Hesselius P, et al. Elevatedpreoperative serum levels of angiogenic cytokines correlate to larger primary tumours and poorer survival in non-small cell lung cancer patients. Lung Cancer. 2002;37(1):57-63.

55. Kraft A, Weindel K, Ochs A, et al. Vascular endothelial growth factor in the sera and effusions of patients with malignant and nonmalignant disease. Cancer. 1999;85(1):178-187.

56. Lin-Hsu I., Wu-Chou S., Jing-Jou Y., Jia-Ming C., Wu-Wei L. Angiogenetic biomarkers in non-small cell lung cancer with malignant pleural effusion: Correlations with patient survival and pleural effusion control. Lung Cancer. 2009;65:371-376. 
57. Grove CS, Lee YC. Vascular endothelial growth factor: the keymediator in pleural effusion formation. Curr Opin Pulm Med. 2002;8:294-301.

58. Nathanson SD. Insights into the mechanisms of lymph node metastases. Cancer. 2003;98:413-423.

59. Cao Y. Emerging mechanisms of tumor lymphangiogenesis and lymphatic metastasis. Nat Rev Cancer. 2005;5:1-9.

60. Stacker SA, Achen MG, Jussila L, Baldwin ME, Alitalo K. Lymphangiogenesis and cancer metastases. Nat Rev Cancer. 2002;2:573-583

61. Ishii $H$, Yazawa $T$, Sato $H$, Suzuki $T$, Ikeda $M$, Hayashi $Y$, et al. Enhancement of pleural dissemination and lymph node metastases of intrathoracic lung cancer cells by vascular endothelial growth factors (VEGFs). Lung Cancer. 2004;45:325-337.

62. Saintigny P., Kambouchner M., Li M., et al. Vascular endothelial growth factor-C and its receptor VEGFR-3 in non-small-cell lung cancer: Concurrent expression in cancer cells from primary tumour and metastatic lymph node, Lung Cancer. 2007;58:205-213.

63. He Y, Rajantie I, Pajusola K, Jeltsch M, Holopainen T, Yla-Herttuala S, et al. Vascular endothelial cell growth factor receptor 3-mediated activation of lymphatic endothelium is crucial for tumor cell entry and spread via lymphatic vessels. Cancer Res. 2005;65:4739-4746.

64. Achen MG, Williams RA, Baldwin ME, Lai P, Roufail S, Alitalo K, et al. The angiogenic and lymphangiogenic factor vascular endothelial growth factor-D exhibits a paracrine mode of action in cancer. Growth Factors. 2002;20:99-107.

65. Kerbel RS, Kamen BA. The anti-angiogenic basis of metronomic chemotherapy. Nat Rev Cancer. 2004;4:423-436.

66. Johnson DH, Fehrenbacher L, Novotny WF, Herbst RS, Nemunaitis JJ, Jablons DM, et al. Randomized phase II trial comparing bevacizumab plus carboplatin and paclitaxel with carboplatin and paclitaxel alone in previously untreated locally advanced or metastatic non-small-cell lung cancer. J Clin Oncol. 2004;22:2184-2191.

67. Reck M, Crino L. Advances in anti-VEGF and anti-EGFR therapy for advanced non-small cell lung cancer, Lung Cancer. 2009;63:1-9.

68. National Comprehensive Cancer Network. Clinical Practice Guidelines in Oncology: Non-Small Cell Lung Cancer v.2.2008. Available at: http:// www.nccn.org/professionals/physician gls/PDF/nscl.pdf. 